\title{
Identification of an outer-membrane haemoglobin-binding protein in Neisseria meningitidis
}

\author{
B. Craig LeE* and Priscilla Hill
}

Department of Microbiology and Infectious Diseases, University of Calgary, 3330 Hospital Drive NW, Calgary, Alberta, Canada T2N 4NI

(Received 4 June 1992; revised 24 August 1992; accepted 26 August 1992)

\begin{abstract}
Although Neisseria meningitidis can use haemoglobin as an iron source in vitro, the mechanism of haemoglobin-iron uptake is unknown. Using a biotinylated human haemoglobin probe in a solid-phase dot-binding assay, haemoglobin-binding activity was detected in total membranes derived from meningococci grown under ironlimited but not iron-sufficient conditions. In competition binding experiments, bovine and human haemoglobin could abrogate binding. In contrast, no binding inhibition was seen with ferric nitrate, protoporphyrin IX, and ironloaded human transferrin. The ability of both haemin and catalase, a nonhaemoglobin haem-containing compound, to inhibit binding competitively suggested that the ligand recognized by the binding protein is the haem moiety. Scatchard plot analysis revealed a heterogeneous receptor population. Limited proteolysis with proteinase $K$ abolished binding activity, suggesting a haemoglobin-protein interaction. Detection of activity in a whole-cell binding assay demonstrated that this haemin-binding protein was surface exposed. In a limited survey of meningococcal strains, the presence of haemoglobin-binding activity in all isolates indicated that expression of this binding protein is not serogroup specific.
\end{abstract}

\section{Introduction}

Neisseria meningitidis, a Gram-negative diplococcus, is an obligate human pathogen (DeVoe, 1982). Meningococcal disease, whose principal clinical expression is meningitis, continues to exert significant worldwide morbidity and mortality (Greenwood, 1984; Peltola, 1983). In the United States, this organism is the second most common cause of bacterial meningitis (Harrison \& Broome, 1987; Schlech et al., 1985), with an annual incidence of one to three per 100000 confined to small focal outbreaks or case clusters (Harrison \& Broome, 1987; Schlech et al., 1985). In contrast, epidemics of group A meningococcal meningitis occur at ten to twelve year intervals in the 'meningitis belt' of sub-Saharan Africa, with an attack rate of $1 \%$ of the population and with an estimated annual incidence of 70 per 100000 (Greenwood, 1984; Peltola, 1983).

A plethora of epidemiological and experimental evidence supports the premise that the ability of a

\footnotetext{
- Author for correspondence. Tel. (403) 2205057 ; fax (403) 2708520.
}

Abbreviations: BHI, brain-heart infusion; biotin-X-NHS, biotinyl$\varepsilon$-aminocaproic acid $N$-hydroxysuccinimide ester; EDDA, ethylenediamine di-o-hydroxyphenylacetic acid; SA-HRP, streptavidin-horseradish peroxidase conjugate. bacterial pathogen to acquire iron is a critical determinant in pathogenesis (Bullen, 1981; Finklestein et al., 1983; Weinberg, 1984). The meningococcus is no exception. One such example is the enhanced lethality of meningococci following the addition of iron-dextran (Holbein, 1980) or iron-loaded transferrin (Holbein, 1981 ; Schryvers \& Gonzalez, 1989) in a murine infection model. Similar observations pertain to the growthpromoting effects of haemoglobin (Brodeur et al., 1985).

The mechanism of iron acquisition in $N$. meningitidis is unique. Whereas most human bacterial pathogens utilize siderophores, low-molecular-mass compounds that chelate iron followed by binding to their cognate receptor and subsequent internalization (Crosa, 1989; Neilands, 1982), as exemplified by the enterobactin system in Escherichia coli (Crosa, 1989), the meningococcus produces no siderophores (Simonson et al., 1982). Rather, this bacterium uses a siderophore-independent receptor-mediated pathway to acquire iron from lactoferrin (Archibald \& DeVoe, 1979; Schryvers \& Morris, $1988 a$ ) and transferrin (Schryvers \& Morris, 1988b). A similar system is operative in Neisseria gonorrhoeae (Lee \& Schryvers, 1988) and Haemophilus influenzae (Schryvers, 1989).

Although haem and haemoglobin can supply the requisite iron for growth of iron-limited meningococci in 
vitro (Mickelsen \& Sparling, 1981) and in vivo (Schryvers \& Gonzalez, 1989; Brodeur et al., 1985), nothing is known of the mechanism of haem-iron uptake. Several observations have implied that a separate receptormediated process is involved in the uptake of haem-iron. Firstly, a pleiotropic meningococcal iron-uptake mutant that has lost the ability to use either lactoferrin or transferrin as the sole iron substrate has retained the ability to use haem (Dyer et al., 1988). Secondly, human haemoglobin is incapable of binding to either the meningococcal lactoferrin (Schryvers \& Morris, 1988a) or transferrin receptor (Schryvers \& Morris, 1988b). This evidence suggests that the haem-iron utilization pathway in $N$. meningitidis is distinct from that of lactoferrin and transferrin and, furthermore, suggests that a haembinding protein exists in $N$. meningitidis that is different from either the lactoferrin or the transferrin receptor. Therefore, assuming that the initial event in haemiron uptake proceeds via such an analogous receptormediated interaction, the objective of this study was to identify such a cell-surface component by developing a solid-phase dot-binding assay specific for this constituent.

\section{Methods}

Bacterial strains and growth conditions. N. meningitidis B16B6, a standard serotyping strain, is a serogroup B, serotype $2 \mathrm{~A}$ strain kindly provided by $A$. Schryvers (University of Calgary, Calgary, AB, Canada). Clinical meningococcal isolates representing serogroups $A$, C, X, Y and W135 were obtained from Foothills Hospital, Calgary, Alberta, Canada. Pseudomonas cepacia $715 \mathrm{j}$ (McKevitt et al., 1989) was supplied by D. E. Woods (University of Calgary, Calgary, AB, Canada). Escherichia coli Sure strain was obtained from Stratagene. Organisms were maintained as stock cultures in skimmed milk at $-70^{\circ} \mathrm{C}$ and, prior to use, were grown on chocolate agar plates supplemented with $1 \%(\mathrm{v} / \mathrm{v}) \mathrm{CVA}$ enrichment (Gibco) at $35^{\circ} \mathrm{C}$ in an atmosphere containing $5 \%(\mathrm{v} / \mathrm{v}) \mathrm{CO}_{2}$

Chemicals. Human and bovine haemoglobins, bovine catalase, equine cytochrome $c_{1 \mathrm{II}}$, iron-loaded human transferrin, bovine haemin, ferric nitrate, protoporphyrin IX and EDDA (ethylenediamine di- $o$-hydroxyphenylacetic acid) were purchased from Sigma. All the iron- and haem-containing compounds were more than $95 \%$ pure according to the manufacturer. Desferrioxamine was obtained from Ciba-Geigy Canada. Proteinase $\mathbf{K}$ was obtained from Gibco BRL. Streptavidin-horseradish peroxidase (SA-HRP) conjugate was from Bio/Can Scientific. Biotin-X-NHS (biotinyl- $\varepsilon$-aminocaproic acid $N$-hydroxysuccinimide ester) was from Calbiochem. With the exception of bovine haemin, which was dissolved in a small volume of $10 \mathrm{~mm}-\mathrm{NaOH}$, and protoporphyrin IX, which was solubilized in a small volume of $10 \mathrm{~mm}$-acetic acid, all of the iron and haem-containing compounds were solubilized in deionized water immediately prior to use.

Biotinylation of human haemoglobin. Preparations of human haemoglobin were equilibrated with $50 \mathrm{~mm}$ - Tris/ $\mathrm{HCl}$ buffer, $\mathrm{pH} 7 \cdot 5$, by cycles of gel filtration and ultrafiltration and diluted to $1 \mathrm{mg} \mathrm{ml}^{-1}$. BiotinX-NHS $(250 \mu \mathrm{g})$ dissolved in $16 \mu \mathrm{l}$ dimethylformamide was added to each millilitre of the protein solution, and the mixture was incubated with gentle agitation at $4{ }^{\circ} \mathrm{C}$ for $2 \mathrm{~h}$. The reaction was terminated by the addition of $100 \mathrm{ml}$ glycine $\left(10 \mathrm{mg} \mathrm{ml}^{-1}\right)$ to each $1 \mathrm{ml}$ portion, and the mixture was incubated for a further $2 \mathrm{~h}$ at $4{ }^{\circ} \mathrm{C}$. To remove excess unbound biotin, the samples were dialysed against three changes of $50 \mathrm{~mm}-\mathrm{Tris} / \mathrm{HCl} \mathrm{pH} 8.0,100 \mathrm{mM}-\mathrm{NaCl}$ and one change of $50 \mathrm{~mm}$ Tris/ $\mathrm{HCl} \mathrm{pH} 7.5$. The dialysed samples were concentrated with an Amicon filter cone and stored at $4{ }^{\circ} \mathrm{C}$.

Membrane preparation. Crude total membranes were prepared as previously described (Lee \& Schryvers, 1988) from cells grown in ironreplete (brain-heart infusion [BHI] broth [Difco] alone) and ironlimited BHI broth (rendered iron-deficient by the addition of an iron chelator, either EDDA or desferrioxamine, to a final concentration of $100 \mu \mathrm{M})$ conditions. Fractionation of total membranes into outer and inner membrane components was achieved by selective detergent solubilization using Triton X-114 (Schnaitman, 1971).

Growth curves. To evaluate the ability of various haem-containing proteins to serve as the sole exogenous source of iron for $N$. meningitidis B16B6, a series of growth experiments was conducted. After $12 \mathrm{~h}$ of growth at $35{ }^{\circ} \mathrm{C}$ in an atmosphere of $5 \%(v / v) \mathrm{CO}_{2}$ on chocolate agar, organisms were inoculated into $\mathrm{BHI}$ broth rendered iron-deficient by the addition of $100 \mu \mathrm{M}-\mathrm{EDDA}$ to a starting $\mathrm{OD}_{600}$ of 0.010 , as measured using a Pye Unicam PU8800 spectrophotometer (Unicam Analytical). This culture was shaken at $35^{\circ} \mathrm{C}$ in an atmosphere of $5 \%$ $\mathrm{CO}_{2}$ until mid-exponential phase growth was achieved $\left(\mathrm{OD}_{600}\right.$ $0.12-0 \cdot 14)$. Aliquots were removed to inoculate, to an initial $O_{600}$ of 0.010 , fresh pre-warmed BHI broth containing $100 \mu \mathrm{M}$-EDDA to which were added the various haem sources at molar equivalent amounts of haem. Growth at $35{ }^{\circ} \mathrm{C}$ in $5 \% \mathrm{CO}_{2}$ was monitored hourly. All experiments were performed in triplicate.

Haemoglobin-binding assay. Haemoglobin-binding activity was detected using a solid-phase dot-binding assay. For the whole-cell binding assay, $12-14 \mathrm{~h}$ old organisins, that had been previously streaked on to chocolate agar and incubated at $35^{\circ} \mathrm{C}$ in the presence of $5 \% \mathrm{CO}_{2}$, were suspended in $\mathrm{BHI}$ broth, with and without $100 \mu \mathrm{M}$ EDDA, to an initial $O_{600}$ of 0.04 , as measured using the Pye Unicam PU8800 spectrophotometer. These cultures were shaken at $35^{\circ} \mathrm{C}$ in the presence of $5 \% \mathrm{CO}_{2}$ or in an anaerobic chamber (model $800 \mathrm{~A}$; Anaerobe Systems) rendered microaerophilic $\left(5 \% \mathrm{O}_{2}, 10 \% \mathrm{CO}_{2}, 85 \%\right.$ $\mathrm{N}_{2}$, by vol.), until mid-exponential phase growth was achieved $\left(\mathrm{OD}_{600}\right.$ $0 \cdot 12-0 \cdot 14)$. Aliquots were removed and used to inoculate fresh prewarmed BHI broth with and without $100 \mu \mathrm{M}$-EDDA. Following this second growth cycle to ensure depletion of internal iron stores, aliquots were again removed at mid-exponential phase and the $\mathrm{OD}_{600}$ was

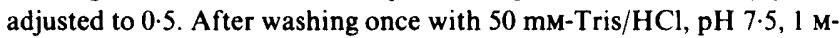
$\mathrm{NaCl}, 100 \mu \mathrm{l}$ of each suspension (approximately $10^{7} \mathrm{c.f} . \mathrm{u}$.) was filtered on to nitrocellulose/cellulose acetate paper (Immobilon-NC, 0.45 micron HAHY paper, Millipore Canada) using a 96-well filter manifold (Minifold I, Schleicher and Schuell), and the paper was allowed to air dry. After blocking with $2 \%(\mathrm{v} / \mathrm{v})$ Blotto $(2 \%$ skimmed milk in TBS [50 mm-Tris/ $\mathrm{HCl}, \mathrm{pH} 7.5,1 \mathrm{M}-\mathrm{NaCl}]$ ) at $37^{\circ} \mathrm{C}$ for $2 \mathrm{~h}$, the paper was washed three times with TBS. Biotinylated human haemoglobin was added in blocking solution at a concentration of $50 \mathrm{~nm}$. The binding mixture was incubated at $37^{\circ} \mathrm{C}$ for $1 \mathrm{~h}$. The blot was washed three times with TBS prior to the addition of SA-HRP conjugate at a concentration of $500 \mathrm{ng} \mathrm{m}^{-1}$ in blocking solution. After a further incubation at $37^{\circ} \mathrm{C}$ for $1 \mathrm{~h}$, followed by washing three times with TBS, the paper was developed with a chloronaphthol/hydrogen peroxide substrate mixture (HRP reagent, Bio-Rad) at room temperature for 5-20 min. The paper was washed with water to stop the reaction. Identical experiments were performed with total membranes, as described below. Specific binding was defined as the difference between biotinylated human haemoglobin bound in the presence and in the absence of $100 \times$ concentration of nonbiotinylated human haemoglobin. Identical experiments were performed using $100 \mu \mathrm{M}$ desferrioxamine, in lieu of EDDA, as the iron chelator. 
Competition binding assay. To assess the specificity of binding, competition binding assays with various iron- and haem-containing proteins were performed. Whole cells, which had undergone two cycles of iron-limited growth as described above, were applied to nitrocellulose paper. The paper was air dried and blocked in $2 \%$ Blotto at $37^{\circ} \mathrm{C}$ for $2 \mathrm{~h}$. Increasing concentrations of the various competing ligands were mixed with a fixed saturating concentration of biotinylated human haemoglobin ( $50 \mathrm{nM}$ ). The paper was secured in a microdot apparatus and the mixtures were loaded into separate wells at a volume of $200 \mu \mathrm{l}$. After incubating the apparatus at $37^{\circ} \mathrm{C}$ for $1 \mathrm{~h}$, any solutions remaining in the wells were removed by filtration. The paper was removed, washed three times with TBS, and developed as described above.

Total membrane binding assay. Suspensions $(2 \mu \mathrm{l})$ of crude total membranes, adjusted to a final concentration of $1 \mathrm{mg} \mathrm{ml}^{-1}$ in $50 \mathrm{mM}$ $\mathrm{Tris} / \mathrm{HCl}, \mathrm{pH} 7 \cdot 5$, or dilutions, were immobilized onto Immobilon-NC paper, permitted to air dry and then blocked with $2 \%$ Blotto for $2 \mathrm{~h}$ at $37^{\circ} \mathrm{C}$. The paper was probed with biotinylated human haemoglobin as described above. Competition assays were conducted using the protocol described for the whole-cell binding assay.

Response to iron limitation. Two approaches were used to determine whether the expression of haemoglobin-binding activity was iron regulated. First, $N$. meningitidis $\mathrm{B} 16 \mathrm{~B} 6$ was grown in broth cultures in which iron limitation was progressively imposed by the addition of increasing concentrations of EDDA (from 0 to $150 \mu \mathrm{M}$ ). Samples from these cultures at mid-exponential phase growth were examined for haemoglobin-binding activity. Second, $\mathrm{Fe}\left(\mathrm{NO}_{3}\right)_{3}(150 \mu \mathrm{M})$ and bovine haemin $(12 \mu \mathrm{M})$ were added to iron-starved cultures of $N$. meningitidis B16B6 and served as the sole source of exogenous iron. Aliquots were removed at mid-exponential phase growth and examined for haemoglobin-binding activity as described above.

Quantification of haemoglobin-binding activity. This was done by scanning the blots with a Zeineh video laser densitometer model SLD 1D/2D set in reflectance mode interfaced with an IBM PC computer incorporating the 1D/2D Soft Laser Scanning software package (Biomed Instruments, Fullerton, CA, USA).

Assessment of whole-cell integrity. The extent of cell lysis of cells that were grown under iron-rich and iron-restricted conditions was assessed visually by phase-contrast microscopy using an Olympus model $\mathrm{BH}-2$ microscope; and biochemically by the presence of NADH oxidase activity, a cytoplasmic membrane-bound enzyme (Osborne et al., 1972). Sonicated whole-cell samples and the $50 \mathrm{~mm}-\mathrm{Tris} / \mathrm{HCl}$ buffer, pH 8.0, served as the positive and negative controls, respectively, for the NADH oxidase enzyme assay.

Proteolytic digestion of $N$. meningitidis whole cells. Aliquots $(1 \mathrm{ml})$ of cells prepared for the whole-cell assay (see above) underwent timed proteolytic digestion at $37^{\circ} \mathrm{C}$ with addition of proteinase $\mathrm{K}$ to a final concentration of $50 \mu \mathrm{g} \mathrm{ml}^{-1}$. Proteolysis was terminated after 5,10 , and $30 \mathrm{~min}$ intervals with the addition of the serine protease inhibitor PMSF to a final concentration of $200 \mu \mathrm{g} \mathrm{ml}^{-1}$. The resultant digests were subjected to the whole-cell binding assay.

Identification of the meningococcal transferrin-binding protein. Transferrin-binding protein activity was assessed by using a horseradish peroxidase probe in the previously described solid-phase dot enzyme assay (Schryvers \& Morris, 1988a).

Protein concentration determination. Protein concentrations were determined by the Lowry method with bovine serum albumin as a standard.

Electrophoresis. Biotinylated and nonbiotinylated human haemoglobin were analysed by nondenaturing PAGE using a modification of the discontinuous buffer system of Laemmli (1970), in which 2-mercaptoethanol and SDS were omitted from the sample and running buffers and the sample was not subjected to thermal denaturation before electrophoresis. Gels comprised $5 \%$ (w/v of acrylamide) stacking and $12 \%(\mathrm{w} / \mathrm{v}$ of acrylamide) separating components with $0.8 \%$ bisacrylamide. The resultant gels were stained with silver (Oakley et al., 1980). Biotinylated and unlabelled human haemoglobin separated in duplicate gel portions were electroblotted on to nitrocellulose membranes by the method of Towbin et al. (1979). The membranes were subsequently probed with the SA-HRP conjugate and developed with chloronaphthol/hydrogen peroxide substrate.

\section{Results}

\section{Biotinylated human haemoglobin}

When subjected to nondenaturing PAGE and stained with silver, the biotinylated human haemoglobin migrated as a single band identical to that of the unlabelled authentic human haemoglobin standard (data not shown). When the corresponding electroblot was probed with the SA-HRP conjugate and developed with the chloronaphthol substrate, a single band was seen with the transferred biotinylated haemoglobin (Fig. 1, lane B). This band exhibited the same mobility as the unlabelled and biotinylated haemoglobins separated by PAGE and silver-stained (data not shown). The absence of a signal emanating from the electroblotted unlabelled human haemoglobin (Fig. 1, lane A) indicated that the band detected from the biotinylated haemoglobin (Fig. 1, lane B) was due to specific interaction of the SA-HRP conjugate with the biotin moiety of the transferred protein, and did not represent nonspecific binding of the conjugate to haemoglobin itself. These results provide evidence that no significant degradation of the ligand occurred during the biotinylation procedure.

\section{Haemoglobin-binding assay}

Preliminary experiments to determine the time course of association of the biotinylated human haemoglobin with iron-restricted $N$. meningitidis whole cells grown to midexponential phase indicated that equilibrium occurred at $1 \mathrm{~h}$ at $37^{\circ} \mathrm{C}$ (data not shown). Binding at $4{ }^{\circ} \mathrm{C}$ or $25^{\circ} \mathrm{C}$ produced identical results (data not shown). In view of the necessity for equilibrium binding for Scatchard analysis, all subsequent binding experiments were performed for $1 \mathrm{~h}$ at $37^{\circ} \mathrm{C}$. Haemoglobin-binding activity required the presence of both whole cells and the biotinylated ligand (Fig. 2, A). When cells were not applied to the nitrocellulose membrane, no binding activity was seen (Fig. 2, D). This result eliminated the possibility that nonspecific attachment of the probe to the Immobilon-NC paper contributed to the observed signal. Similarly, no signal was seen when the chloronaphthol substrate alone was added to immobilized 
A

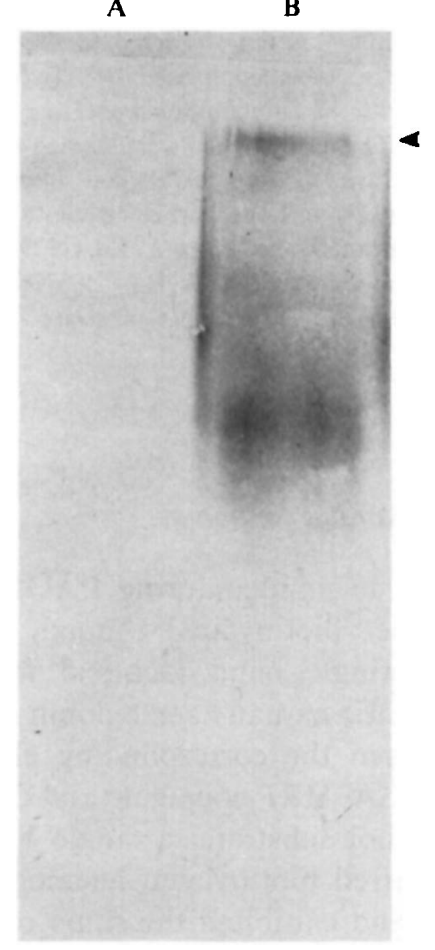

Fig. 1. Electroblot of biotinylated human haemoglobin. Five micrograms each of human haemoglobin (lane A) and biotinylated human haemoglobin (lane B) were separated in a $12 \%$ nondenaturing PAGE as described in Methods. The separated proteins were electroblotted on to a nitrocellulose membrane and probed with SA-HRP. The blot was developed by the addition of chloronaphthol substrate. The arrowhead indicates biotinylated protein in the stacking-separating gel interface that failed to enter into the separating gel.
A

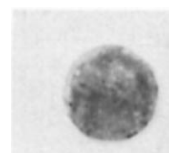

B

C

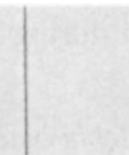

Fig. 2. Biotinylated human haemoglobin solid-phase dot-binding assay. Aliquots $\left(10^{7}\right.$ c.f.u. $)$ of $N$. meningitidis $\mathrm{B} 16 \mathrm{~B} 6$ grown under ironrestrictive conditions were immobilized on to nitrocellulose membrane. Cells were probed with the biotinylated human haemoglobin followed by the SA-HRP conjugate and the chloronaphthol substrate, as described in Methods (A); chloronaphthol substrate alone (B); and SA-HRP conjugate followed by the chloronaphthol substrate (C). In sample $D$, the nitrocellulose membrane without applied cells was probed for binding activity using the dot-binding protocol.

whole cells (Fig. 2, B), indicating that intrinsic peroxidase activity present in the whole-cell membranes was not responsible for binding activity. The absence of a signal with the addition of the SA-HRP alone to the whole cells also excluded nonspecific binding of this conjugate to the whole cell preparations (Fig. 2, C). Identical results were obtained using iron-limited total membranes (data not shown).
Fig. 3(a) shows the effect of increasing amounts of iron-limited whole cells on biotinylated human haemoglobin ligand binding. Total human haemoglobin binding increased in proportion to the amount of whole cells immobilized on the nitrocellulose, whereas nonspecific binding was negligible (data not shown). In the reciprocal experiments when $10^{7}$ c.f.u. of iron-starved whole cells were incubated with increasing amounts of biotinylated human haemoglobin, saturable binding was observed (Fig. 3b). Scatchard analysis (Scatchard, 1946) of the binding data revealed a curvilinear plot, indicating the presence of two populations of binding protein (Fig. $3 c$ ). A high-affinity receptor with an apparent dissociation constant, $K_{\mathrm{d}}$, of $2.52 \times 10^{-7} \mathrm{M}$ co-existed with a low-affinity receptor $\left(K_{\mathrm{d}} 7.9 \times 10^{-6} \mathrm{M}\right)$. Because all the available unoccupied binding sites would not be exposed by using the dot-binding assay, as would presumably occur with the more traditional binding-assay methods of equilibrium and flow dialysis, these kinetic data represent a minimal estimate. Alternatively, the presence of a heterogeneous receptor population may be an artifact of the dot-binding assay, and this interpretation cannot be excluded.

\section{Specificity of whole-cell binding for human haemoglobin}

The specificity of whole-cell binding activity for human haemoglobin was addressed in a series of competition experiments. The binding of biotinylated human haemoglobin to meningococci was specifically blocked by competition with unlabelled bovine haemin and the haemoproteins human haemoglobin, bovine haemoglobin and bovine catalase in a concentration-dependent manner (Fig. $4 a$ ). In contrast, no binding inhibition was observed with another haem-containing protein, equine cytochrome $c_{111}$ (Fig. $4 b$ ); or with protoporphyrin IX, the immediate precursor of haem in the haem biosynthetic pathway (data not shown). Iron-loaded human transferrin, a nonhaem iron-containing glycoprotein, and $\mathrm{Fe}\left(\mathrm{NO}_{3}\right)_{3}$ also failed to competitively inhibit binding of biotinylated human haemoglobin to meningococcal cells (Fig. $4 b$ ). Identical results were seen with iron-limited total membranes (data not shown).

\section{Growth curves}

The functional correlates of this binding specificity were determined by examining the ability of the various competing haem-containing ligands to support the growth of iron-restricted cultures of meningococci. A representative experiment is shown in Fig. 5. The results recapitulated those seen in competition assays. Bovine haemin, human and bovine haemoglobin, and bovine catalase could each serve as the sole exogenous iron 

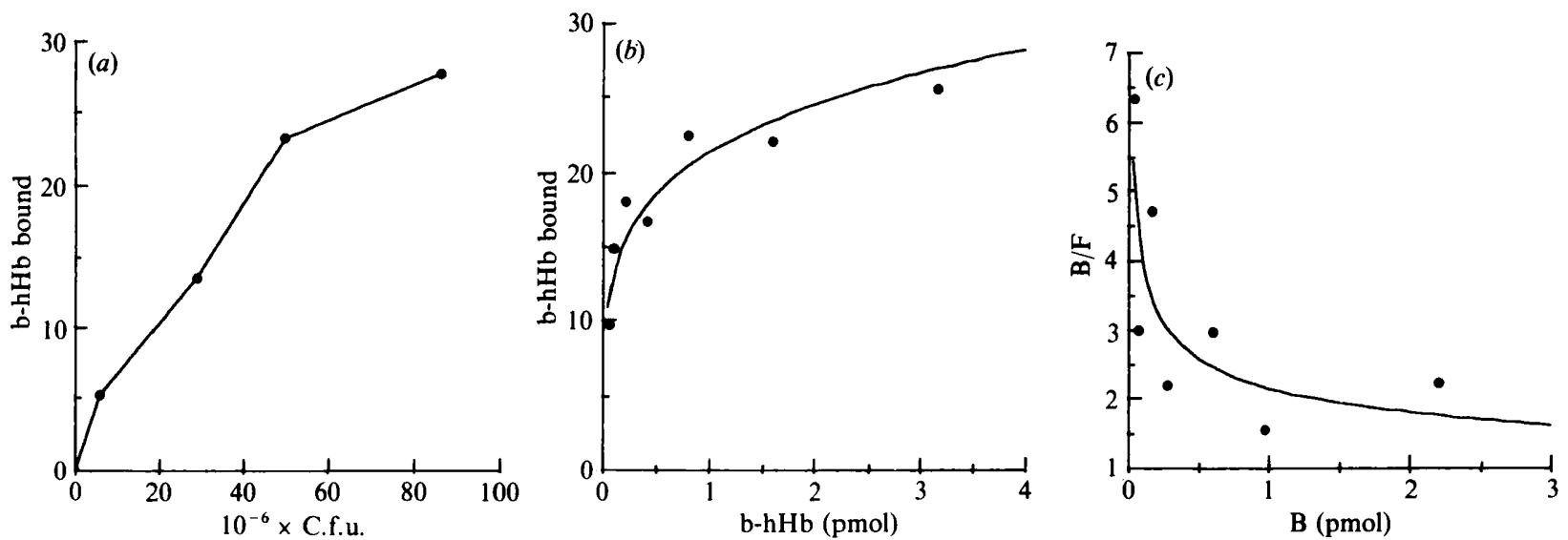

Fig. 3. Kinetics of the biotinylated human haemoglobin (b-hHb) solid-phase dot-binding assay. (a) Concentration response curve for number of bacteria per spot binding to biotinylated human haemoglobin. Aliquots of $N$. meningitidis B16B6 grown under iron-limited conditions were applied on to nitrocellulose filters, incubated with blocking buffer, and then probed for haemoglobin-binding activity with biotinylated human haemoglobin in the presence or absence of 100 -fold excess of unlabelled human haemoglobin. After developing, the blots were quantified using a scanning densitometer. The amount of haemoglobin bound is expressed as the area under the peaks, in arbitrary units. Results depict specific binding. Specific binding was determined by subtracting nonspecific binding from total binding. (b) Saturability of biotinylated human haemoglobin binding. A fixed amount of meningococci grown under ironrestricted conditions $\left(10^{7}\right.$ c.f.u.) was immobilized on to triplicate nitrocellulose membranes which were probed with increasing concentrations of biotinylated human haemoglobin $(0.496-62.5 \mathrm{nM})$ in the presence or absence of 100 -fold excess unlabelled human haemoglobin. After developing, specific binding activity was quantified as in $(a)$. The results in $(a)$ and $(b)$ each represent the means of three experiments performed in duplicate. (c) Scatchard analysis of specific binding of biotinylated human haemoglobin to $N$. meningitidis B16B6. B, bound; F, free.

source for the growth of iron-limited meningococci. Biotinylated human haemoglobin retained the capacity to function as an iron substrate, indicating that its chemical modification did not significantly impair its legitimacy as an authentic ligand. In contrast, consistent with its inability to inhibit binding in the competition studies, cytochrome $c_{\mathrm{III}}$ could not support the growth of iron-restricted meningococci. The optical densities of all the cultures measured after $24 \mathrm{~h}$ of growth were identical to that seen after $5 \mathrm{~h}$, indicating that stationary growth was achieved at $5 \mathrm{~h}$ (data not shown).

\section{Assessment of whole-cell integrity}

Cells grown under either iron-limited or iron-rich conditions and subsequently suspended in Tris buffer were intact when examined by phase-contrast microscopy (data not shown). In contrast, only fragmented cells and cell debris were seen in the sonicated samples (data not shown). Minimal NADH oxidase activity was detected in the supernatant of cells grown under either iron-limited or iron-rich conditions (data not shown). The whole-cell lysates demonstrated pronounced NADH oxidase activity (data not shown). Control mixtures comprising either the Tris buffer or supplemented BHI broth with and without $100 \mu \mathrm{M}$-EDDA were devoid of NADH oxidase activity. These results indicated that whole-cell integrity was maintained in the cultures used in the whole-cell binding assay. The minimal cell lysis present excluded significant contamination of the wholecell aliquots with intracellular sequestered haem-containing compounds, such as cytochrome proteins.

\section{Cellular localization of the meningococcal haemoglobin-binding protein}

Haemoglobin-binding activity was present in Tritoninsoluble membrane extracts derived from crude total membranes prepared from cells grown under irondeficient conditions (Fig. 6a). In contrast, no haemoglobin-binding activity was observed in the Tritonsoluble membrane fraction (Fig. $6 a$ ). Because membrane partitioning is preferential by detergent solubilization and not absolute, this result implied that the cell component possessing the haemoglobin-binding property resided in the outer membrane. The parallel whole-cell binding studies that were conducted corroborated its outer membrane topography. The expression of haemoglobin-binding activity from whole cells grown under iron-limited conditions (Fig. $6 b$ ), and not from whole cells grown under iron-rich conditions (Fig. 6b), indicated that this haemoglobin-binding moiety was both surface exposed and iron regulated. No signal was present when iron-limited supplemented BHI medium alone was subjected to the solid-phase dot-binding protocol (data not shown). 


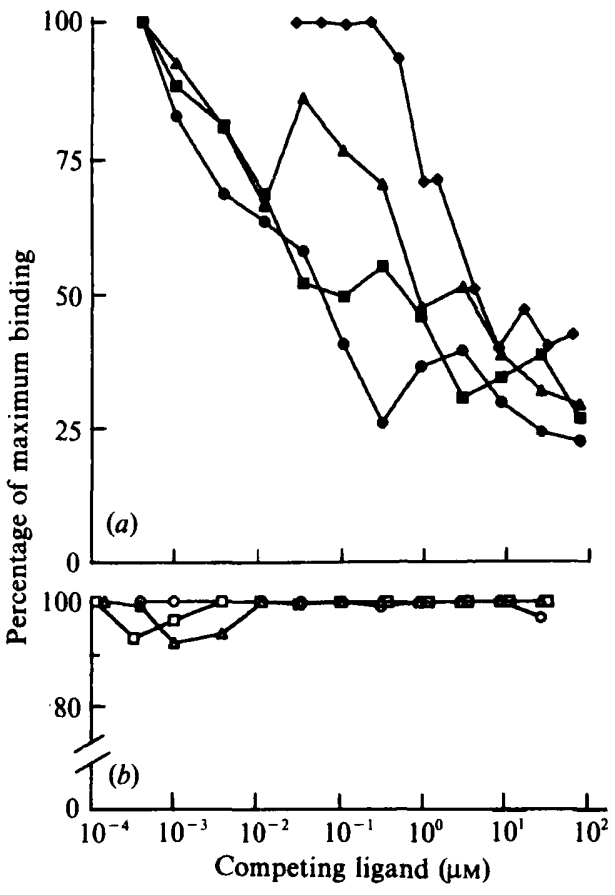

Fig. 4. Specificity of meningococcal haemoglobin-binding activity. (a) Effects of different haemoproteins on biotinylated human haemoglobin binding. Dot-blots of iron-limited meningococci $\left(10^{7}\right.$ c.f.u.) prepared as described in the text were probed in competitive assays with biotinylated human haemoglobin $(50 \mathrm{nM})$ in the presence of increasing concentrations of human haemoglobin $(\bullet)$, bovine haemoglobin ( $\mathbf{\square})$, bovine haemin $(\boldsymbol{\nabla})$, and bovine catalase ( $\mathbf{\Delta}$ ). Maximum binding is defined as the amount of biotinylated human haemoglobin associated with $N$. meningitidis B16B6 in the absence of competing ligands. Data represent the mean of three experiments performed in duplicate. (b) Effects of equine cytochrome $c_{\mathrm{III}}(\mathrm{O}), \mathrm{Fe}\left(\mathrm{NO}_{3}\right)_{3}(\square)$, and $100 \%$ iron-loaded human transferrin $(\triangle)$. Competition binding experiments were performed as described in the text. Maximum binding is defined as the amount of biotinylated human haemoglobin retained on the nitrocellulose membranes in the absence of competing ligands. Data represent the mean of three experiments performed in duplicate.

\section{Iron-regulated expression of the haemoglobin-binding protein}

As noted above, haemoglobin-binding activity was only observed in intact whole cells grown in iron-limited conditions (Fig. 6b) and this activity increased with progressive iron restriction (Fig. $6 b$ ). Expression was independent of the iron chelator used to impose iron limitation (Fig. 6b). No binding activity was detected in cells grown under iron-rich conditions (Fig. 6b). Similarly, when iron-limitation was reversed by the addition of $150 \mu \mathrm{M}-\mathrm{Fe}\left(\mathrm{NO}_{3}\right)_{3}$, or $12 \mu \mathrm{M}$-haemin, binding activity was absent (Fig. 6c). These results indicated that haemoglobin-binding activity is iron-repressible. Examination of the crude total membranes that were derived from these cell cultures produced identical results (data not shown). Binding activity was absent in iron-rich

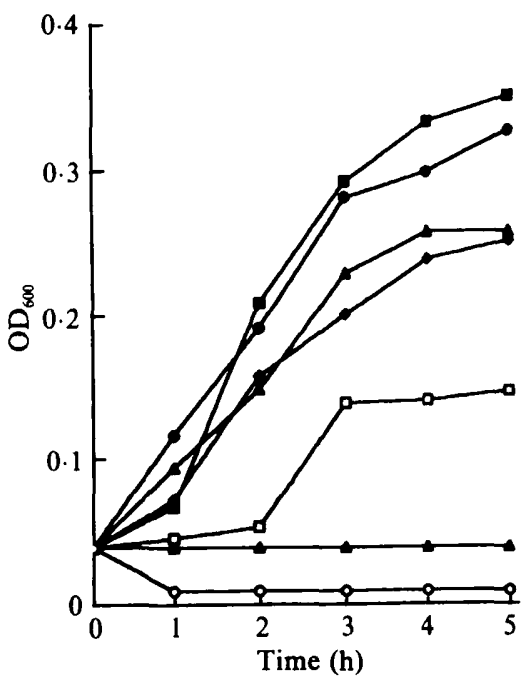

Fig. 5. Growth response of $N$. meningitidis B16B6 in iron-limited BHI broth without additional supplements $(O)$, or with the addition of molar equivalents of haem $(12 \mu \mathrm{M})$ as bovine haemin $(\square)$, human haemoglobin $(\bullet)$, bovine haemoglobin $(\diamond)$, biotinylated human haemoglobin $(\Delta)$, bovine catalase $(\square)$, and equine cytochrome $c_{\mathrm{III}}(\Delta)$.

cultures of meningococci grown under microaerophilic conditions or at $30^{\circ} \mathrm{C}$, indicating that neither oxidative stress nor reduced growth rate governed expression (data not shown).

\section{Proteolytic digestion of meningococcal whole cells}

Pre-incubation of iron-restricted whole cells with proteinase $\mathrm{K}$ abolished receptor activity in a time- and dosedependent fashion (data not shown), suggesting that either a protein determinant(s) is involved in the interaction of the receptor with its ligand or that preservation of the surrounding cellular protein architecture is necessary for binding.

\section{Presence of haemoglobin-binding activity in other meningococcal strains}

In a limited survey of meningococcal isolates, haemoglobin binding activity was discerned in representative strains belonging to serogroups A, C, X, Y and W135 (Fig. 7). This result indicates a functional conservation of the haemoglobin-binding protein among clinically significant serogroups. Under similar iron-limiting conditions, no haemoglobin-binding protein expression was detected in Pseudomonas cepacia or E. coli.

\section{Meningococcal transferrin-binding protein}

Transferrin-binding protein activity was present only under conditions of iron-limitation (data not shown). 
(a)

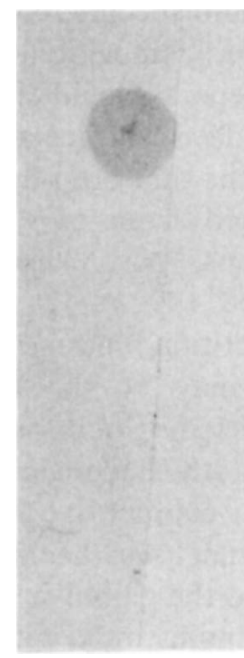

(c)

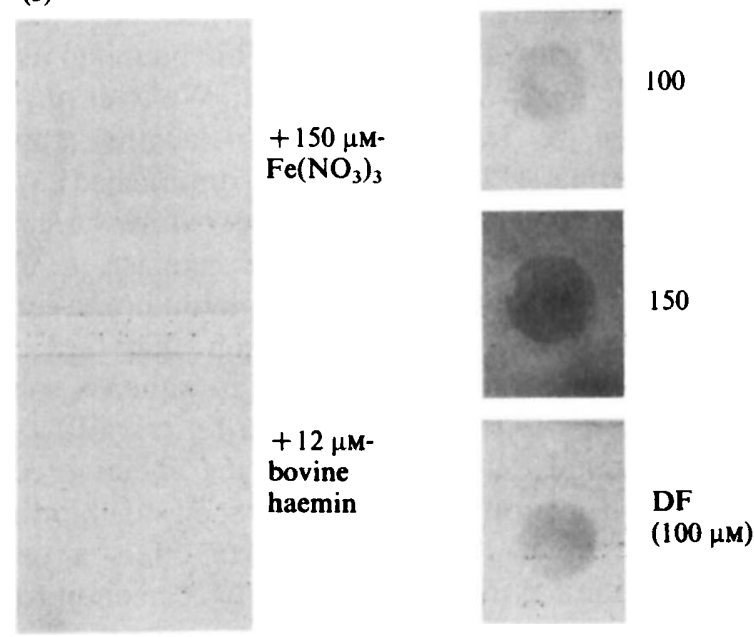

Fig. 6. (a) Outer-membrane location of haemoglobin-binding activity. Crude total membranes from $N$. meningitidis $\mathrm{B} 16 \mathrm{~B} 6$ grown under ironrestricted conditions were solubilized with Triton X-114. Aliquots of the Triton-insoluble and the Triton-soluble fraction (each $3 \mathrm{ng}$ ) were spotted on to nitrocellulose paper and probed for haemoglobin-binding activity as described in Methods. (b) Expression of haemoglobinbinding activity. Cultures of $N$. meningitidis $\mathrm{B} 16 \mathrm{~B} 6$ were grown in the presence of increasing concentrations of EDDA which produced increasing iron restriction. Aliquots from these cultures were examined for haemoglobin-binding activity as described in Methods. The bottom spot represents an aliquot of meningococci from a culture grown in the presence of the iron chelator desferrioxamine (DF). (c) Iron regulation of haemoglobin-binding activity. Iron-starved cultures of $N$. meningitidis $\mathrm{B} 16 \mathrm{~B} 6$ were provided with either $\mathrm{Fe}\left(\mathrm{NO}_{3}\right)_{3}$ or bovine haemin as the sole exogenous iron source at the indicated concentrations. Aliquots were removed at the mid-exponential phase of growth and examined for haemoglobin-binding activity using the solid-phase dot-binding assay as described in Methods.

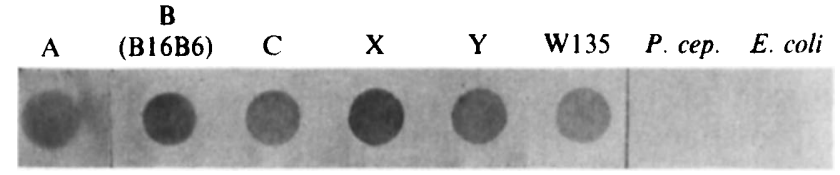

Fig. 7. Haemoglobin-binding activity in other bacteria. Clinical isolates of $N$. meningitidis representing serogroups $\mathrm{A}, \mathrm{B}, \mathrm{C}, \mathrm{X}, \mathrm{Y}$ and $\mathrm{W} 135$, and $P$. cepacia ( $P$. cep.) and $E$. coli Sure strain were grown under iron-limited conditions. Samples were removed at the mid-exponential phase of growth, immobilized on to nitrocellulose membrane, and probed for haemoglobin-binding activity as described in Methods.

Time course experiments showed that transferrinbinding protein expression occurred concurrently with haemoglobin-binding activity (data not shown). These results internally validated the protocols used for iron starvation and suggested that the expression of both binding proteins is coordinately regulated.

\section{Discussion}

Using a biotinylated human haemoglobin probe, an ironregulated surface-exposed haemoglobin-binding protein has been identified in $N$. meningitidis. The binding kinetics of this protein for haemoglobin exhibit saturability, specificity and reversibility, characteristics satisfying the generally accepted functional definition of a receptor-ligand interaction (Kahn, 1976).

The binding kinetics of the meningococcal haemoglobin-binding protein are compatible with either a cooperative model, in which binding at one site modulates the affinity of the second binding site (Freifelder, 1982), or with a heterogeneous model, in which two independent binding sites compete for haemoglobin binding (Freifelder, 1982). Such receptorligand interactions are common in biological systems (Freifelder; 1982; Gammeltoft, 1984). For instance, a two-component iron-uptake mechanism has been proposed for the lactoferrin receptor in Trichomonas vaginalis (Lehker \& Alderete, 1992).

The meningococcus exhibits a preferential ability to appropriate iron from transferrin relative to haem and haemoglobin (Schryvers \& Gonzalez, 1989). Such a model might account for this functional hierarchy, despite the low $K_{\mathrm{d}}(0.7 \mu \mathrm{M})$ of the transferrin receptor (Tsai et al., 1988). Assuming the presence of two binding sites with two distinct affinities for haemoglobin, binding of haemoglobin to the low-affinity component of the meningococcal haemoglobin-binding protein $\left(K_{\mathrm{d}}\right.$ $7.9 \mu \mathrm{M})$, coupled subsequently with haem-iron translocation across the periplasmic space to the cytosol, may represent the rate limiting step(s) in meningococcal haemoglobin-iron uptake. 
Several reasons may account for the inability of cytochrome $c_{\mathrm{III}}$ to supply the requisite haem-iron for the growth of iron-starved $N$. meningitidis B16B6. One explanation derives from the observation that cytochrome $c_{I I I}$ was incapable of displacing haemin binding in the competition assays. This result implies that this haemoprotein is unable to bind to the haemoglobinbinding protein. Another explanation may be related to the ease of extraction of the haem prosthetic group. Unlike haemoglobin, in which haem release occurs readily under nondenaturing conditions (Smith et al., 1991), haem dissociation in cytochrome $c_{\text {III }}$ would be more difficult owing to the covalent attachment of haem to the polypeptide backbone (Dickerson et al., 1971).

Although the possibility exists that the haemoglobinbinding protein represents a class of cytochrome proteins, this explanation is very unlikely for the following reasons. Most described cytochromes are periplasmic or cytoplasmic membrane-associated moieties (Meyer \& Pistorius, 1989). In contrast, the haemoglobin-binding protein is a surface-exposed outer-membrane protein. Also inconsistent is the lack of enhanced production of the haemoglobin-binding protein under conditions of oxygen stress, a feature of most cytochromes (Gennis, 1987). These properties provide a cogent argument that this haemoglobin-binding protein is not a cytochrome.

The source of haemoglobin for $N$. meningitidis in vivo is unknown. Microangiopathic haemolytic anaemia is a hallmark of invasive meningococcal infection (DeVoe, 1982). This pathological process would liberate intracellular sequestered haemoproteins, such as haemoglobin, permitting their access by meningococci. Although free intravascular haemoglobin is avidly bound to its serum carrier protein haptoglobin, meningococci can successfully scavenge haem from this complex (Dyer et al., 1987).

Because of their propensity to aggregate in aqueous solutions at physiological pH (Brown et al., 1976; MullerEberhard \& Nikkila, 1989), and because of their potential cellular toxicity due to participation in lipid peroxidative catalysis (Vincent, 1989), haem and other tetrapyrroles are always bound to protein (MullerEberhard \& Nikkila, 1989). In man, a plethora of intracellular and extracellular haem-binding proteins have been characterized (Muller-Eberhard \& Nikkila, 1989), some coupling transport with antioxidant functions (Gutteridge \& Smith, 1988). Indeed, haem translocation across eukaryotic cell membranes is postulated to be a function of a haem-specific binding receptor (Galbraith et al., 1985; Galbraith \& McElrath, 1988; Grasbeck et al., 1979; Smith \& Morgan, 1984), whose expression is induced under iron limitation (Smith \& Ledford, 1988).

The biochemical constraints imposed by free haem prompt the speculation that an analogous haem-uptake mechanism exists in $N$. meningitidis, whereby the initial step in haemoglobin-iron uptake involves the interaction with a surface-accessible haemoglobin specific receptor. The iron-regulated outer-membrane haemoglobin-binding protein described in this report would be an attractive functional candidate. Indeed, surface-accessible haemin-specific binding proteins that bind haemoglobin have been recently isolated from two other human-specific bacterial pathogens, $N$. gonorrhoeae (Lee, 1992b) and $H$. influenzae (Lee, 1992a).

Evidence derived from the competition binding assays suggests that the haem moiety may be the ligand recognized by the meningococcal haemoglobin-binding protein. Both catalase, and significantly, haem alone are capable of abrogating binding in the competitive assays. The ability of catalase, a nonhaemoglobin haemoprotein, to inhibit binding suggests that the globin subunits of haemoglobin do not interact significantly with the binding protein. Competition binding experiments using isolated globin chains as the competing ligand may address this issue. However, the marked conformational differences between globin, and globin bound to its haem prosthetic group (Yip et al., 1972; Waks et al., 1973; Leutzinger \& Beychok, 1981) make this approach problematical. Haemin exhibited a diminished capacity, relative to the three other haemoproteins, human and bovine haemoglobin, and bovine catalase, to inhibit binding of the biotinylated haemoglobin probe competitively (Fig. 4a). This observation may reflect the tendency of haemin to aggregate in aqueous solutions (Brown et al., 1976; Muller-Eberhard \& Nikkila, 1989), a characteristic that would reduce the effective concentration of haemin available to compete for binding. In addition, this aggregating property offers a putative explanation for the enhanced ability of haemin to serve as an iron substrate (Fig. 5), despite being less effective at competition (Fig. 4a). The stacking of haemin molecules may permit several haemin moieties to bind to a single receptor, thereby effectively augmenting the ability of haemin to function as an iron source.

Furthermore, the inability of either iron or protoporphyrin IX to inhibit binding competitively suggests that the presence of iron within the tetrapyrrole ring is required for its recognition as a legitimate ligand. Alternatively, the binding protein may display a significant stereospecificity for haemin (iron protoporphyrin IX) relative to other haem analogues, such as protoporphyrin IX. Such a pronounced bias for the preservation of the central iron in the porphyrin ring is mirrored in the increased affinity of eukaryotic plasma membrane haem receptors for iron-containing metalloporphyrins (Galbraith et al., 1985; Galbraith \& McElrath, 1988). In this context, the effectiveness of 
metalloporphyrins with substituted central metals in displacing haemoglobin binding would be of interest.

In conclusion, this study has identified the presence of an iron- and haemin-regulated surface-exposed haemoglobin-binding protein in $N$. meningitidis. Studies are under way to isolate the receptor polypeptide(s) and to delineate its role in haem-iron acquisition.

We thank A. B. Schryvers and D. E. Woods for the generous provision of bacterial strains. This study was supported by a Miles Pharmaceuticals/Canadian Infectious Diseases Society Research Award and by an Alberta Heritage Foundation for Medical Research Clinical Investigator's Award 71-8218.

\section{References}

Archibald, F. S. \& DeVoe, I. W. (1979). Removal of iron from human transferrin by Neisseria meningitidis. FEMS Microbiology Letters 6 , 149-162.

Brodeur, B. R., Larose, Y., Tsang, P., Hamel, J., Ashton, F. \& RyAN, A. (1985). Protection against infection with Neisseria meningitidis group $B$ serotype $2 b$ by passive immunization with serotype-specific monoclonal antibody. Infection and Immunity 50, 510-516.

Brown, S. B., Shillock, M. \& Jones, P. (1976). Equilibrium and kinetic studies of the aggregation of porphyrins in aqueous solutions. Biochemical Journal 153, 279-285.

BulLeN, J. J. (1981). The significance of iron in infections. Reviews of Infectious Diseases 3, 1127-1138.

Crosa, J. H. (1989). Genetics and molecular biology of siderophoremediated iron transport in bacteria. Microbiological Reviews 53, $517-530$.

DEVOE, I. (1982). The meningococcus and mechanisms of pathogenicity. Microbiological Reviews 46, 162-190.

Dickerson, R. E., Takano, T. \& Eisenberg, D. (1971). Ferricytochrome $c$. I. General features of the horse and bonito proteins at $2.8 \AA$ resolution. Journal of Biological Chemistry 246, 1511-1535.

DYer, D. W., West, E. P. \& SPARling, P. F. (1987). Effects of serum carrier proteins on the growth of pathogenic Neisseriae with hemebound iron. Infection and Immunity 55, 2171-2175.

Dyer, D. W., West, E. P., McKenna, W., Thompson, S. A. \& SPARLING, P. F. (1988). A pleiotropic iron-uptake mutant of Neisseria meningitidis lacks a 70-kilodalton iron-regulated protein Infection and Immunity 56, 977-983.

Finklestein, R. A., Sciortino, C. V. \& McIntosh, M. A. (1983). Role of iron in microbe-host interactions. Reviews of Infectious Diseases 5 (Supplement 4), 759-777.

Freifelder, D. (1982). Physical Chemistry. Applications to Biochemistry and Molecular Biology. New York: W. H. Freeman.

Galbraith, R. A. \& McElrath, M. J. (1988). Heme binding to Leishmania mexicana amazonensis. Molecular and Biochemical Parasitology 29, 47-54.

Galbraith, R. A., Sassa, S. \& Kappas, A. (1985). Heme binding to murine erythroleukemia cells. Journal of Biological Chemistry 260, $12198-12202$

GAMMELTOFT, S. (1984). Insulin receptors: binding kinetics and structure-function relationship to insulin. Physiological Reviews 64, 1321-1378.

GenNIS, R. B. (1987). The cytochromes of Escherichia coli. FEMS Microbiology Reviews 46, 387-399.

Grasbeck, R., Kouvonen, I., LUNDBerg, M. \& TENhunen, R. (1979). An intestinal receptor for heme. Scandinavian Journal of Hematology 23, 5-9.

GREENwOOD, B. M. (1984). Selective primary health care: strategies for control of disease in the developing world. XIII. Acute bacterial meningitis. Reviews of Infectious Diseases 6, 374-389.
GutTeridge, J. M. C. \& SMith, A. (1988). Antioxidant protection by haemopexin of haem-stimulated lipid peroxidation. Biochemical Journal 256, 861-865.

HARrison, L. H. \& BroOme, C. V. (1987). The epidemiology of meningococcal meningitis in the civilian U.S. population. In The Evolution of Meningococcal Disease, pp. 27-46. Edited by N. A Vedros. Boca Raton, Florida: CRC Press.

HolbeIN, B. E. (1980). Iron-controlled infection with Neisseria meningitidis in mice. Infection and Immunity 29, 886-891.

HOLBEIN, B. E. (1981). Enhancement of Neisseria meningitidis infection in mice by the addition of iron bound to transferrin. Infection and Immunity 34, 120-125.

K AHN, C. R. (1976). Membrane receptors for hormones and neurotransmitters. Journal of Cell Biology 70, 261-286.

LAEMMLI, U. K. (1970). Cleavage of structural proteins during the assembly of the head of bacteriophage T4. Nature, London 227, 680-685.

LeE, B. C. \& SCHRYvers, A. B. (1988). Specificity of the lactoferrin and transferrin receptors in Neisseria gonorrhoeae. Molecular Microbiology 2, 827-829.

LEE, B. C. (1992a). Isolation of an outer membrane haemin-binding protein from Haemophilus influenzae type b. Infection and Immunity 60, 810-816.

LEE, B. C. (1992b). Isolation of heme-binding proteins of Neisseria gonorrhoeae. Journal of Medical Microbiology 36, 121-127.

LEHKER, M. W. \& ALDERETE, J. F. (1992). Iron regulates the growth of Trichomonas vaginalis and the expression of immunogenic trichomonad proteins. Molecular Microbiology 6, 123-132.

LEUTZINGER, Y. \& BEYCHOK, S. (1981). Kinetics and mechanism of heme-induced refolding of human $\alpha$-globin. Proceedings of the National Academy of Sciences of the United States of America 78, 780-784.

McKevitT, A. I., Bajaksouzian, S., Klinger, J. D. \& Woods, D. E. (1989). Purification and characterization of an extracellular protease from Pseudomonas cepacia. Infection and Immunity 57, 771-778.

MeYer, T. E. \& Pistorius, E. K. (1989). Structure, function and distribution of soluble bacterial redox proteins. Biochimica et Biophysica Acta 975, 1-28.

Mickelsen, P. A. \& Sparling, P. F. (1981). Ability of Neisseria gonorrhoeae, Neisseria meningitidis, and commensal Neisseria species to obtain iron from transferrin and iron compounds. Infection and Immunity 33, 555-564.

MUller-Eberhard, U. \& NikKILA, H. (1989). Transport of tetrapyrroles by proteins. Seminars in Hematology 26, 86-104.

NeILANDS, J. B. (1982). Microbial envelope proteins related to iron Annual Review of Microbiology 36, 285-309.

OAKLeY, B. R., KIRSCH, D. R. \& MORRIS, N. R. (1980). A simplified ultrasensitive silver stain for detecting proteins in polyacrylamide gels. Analytical Biochemistry 105, 361-363.

Osborne, M. J., Gander, J. E., Parisi, E. \& Carson, J. (1972) Mechanism of assembly of the outer membrane of Salmonella typhimurium: isolation and characterization of cytoplasmic and outer membrane. Journal of Biological Chemistry 247, 3962-3972.

Peltola, H. (1983). Meningococcal disease: still with us. Reviews of Infectious Diseases 5, 71-91.

SCATCHARD, G. (1946). The attraction of proteins for small molecules and ions. Annals of the New York Academy of Sciences 51, 660-672.

SChlech, W. F., III, Ward, J. I., Band, J. D., Hightower, A., Fraser, D. W. \& BroOME, C. V. (1985). Bacterial meningitis in the United States, 1978 through 1981. JAMA 253, 1749-1754.

SCHNAITMAN, C. A. (1971). Solubilization of cytoplasmic membrane of Escherichia coli by Triton X-100. Journal of Bacteriology 108, 545-563.

SCHRYVERS, A. B. (1989). Identification of the transferrin- and lactoferrin-binding proteins in Haemophilus influenzae. Journal of Medical Microbiology 29, 121-130.

Schryvers, A. B. \& Gonzalez, G. C. (1989). Comparison of the abilities of different protein sources of iron to enhance Neisseria meningitidis infection in mice. Infection and Immunity 57, 2425-2429.

SCHRYVERS, A. B. \& MORRIS, L. J. (1988a). Identification and characterization of the human lactoferrin-binding protein from Neisseria meningitidis. Infection and Immunity 56, 1144-1149. 
SCHRYVERS, A. B. \& MORRIS, L. J. (1988b). Identification and characterization of the transferrin receptor from Neisseria meningitidis. Molecular Microbiology 2, 281-288.

Simonson, C., Brenner, D. \& DeVoe, I. E. (1982). Expression of a high-affinity mechanism for acquisition of transferrin iron by Neisseria meningitidis. Infection and Immunity 36, 107-113.

SMITH, A. \& LEDFORD, B. E. (1988). Expression of the haemopexintransport system in cultured mouse hepatoma cells. Biochemical Journal 256, 941-950.

Smith, A. \& Morgan, W. T. (1984). Hemopexin-mediated heme uptake by liver. Journal of Biological Chemistry 259, 12049-12053.

Smith, M. L., Paul, J., Ohlsson, P. I., Huortsberg, K. \& Paul, K. G. (1991). Heme-protein fission under nondenaturing conditions. Proceedings of the National Academy of Sciences of the United States of America 88, 882-886.

Towbin, H., Stakhelin, T. \& Gordon, J. (1979). Electrophoretic transfer of proteins from polyacrylamide gels to nitrocellulose sheets: procedure and some applications. Proceedings of the National Academy of Sciences of the United States of America 76, 4350-4354.
TSAi, J., Dyer, D. W. \& Sparling, P. F. (1988). Loss of transferrin receptor activity in Neisseria meningitidis correlates with inability to use transferrin as an iron source. Infection and Immunity 56, 3132-3138.

VINCENT, S. H. (1989). Oxidative effects of heme and porphyrins on proteins and lipids. Seminars in Hematology 26, 105-113.

WAKS, M., YIP, Y. K. \& BEYCHOK, S. (1973). Influence of prosthetic groups on protein folding and subunit assembly. II. Recombination of separated human $\alpha$ - and $\beta$-globin chains with heme and allopex interactions of globin chains with heme-containing subunits. Journal of Biological Chemistry 248, 6462-6470.

WEINBERG, E. D. (1984). Iron withholding: a defense against infection and neoplasia. Physiological Reviews 64, 65-107.

YIP, Y. K., WAKs, M. \& BEYCHOK, S. (1972). Influence of prosthetic groups on protein folding and subunit assembly. I. Conformational differences between separated human $\alpha$ - and $\beta$-globins. Journal of Biological Chemistry 247, 7237-7244. 